\title{
Look for the leaders
}

\section{Leadership skills need to be nurtured early in a career, say Toddi A. Steelman and Jeffrey J. McDonnell.}

$\mathrm{T}$

The election of Donald Trump as US president, and his appointments

for cabinet and executive-office positions, present unprecedented challenges for those who care about science and its role in shaping society. The scientific enterprise needs leadership from researchers to advocate for science and evidence-based, informed decision-making. For that, we need a wave of early-career leaders.

Early-career scientists often think about leadership in a formal sense and at the highest levels - an appointed administrator at a university, an elected leader of a scientific union. But leadership usually starts informally, and for it to take root early in a career, we need to teach and mentor it as we do other acquired skills. But unlike master's of business administration programmes, most US PhD programmes do not provide leadership training.

We have found that leadership skills are cultivated over time. Incremental opportunities for increasing and diversifying leadership experiences are key for junior researchers to gain confidence, express ideas publicly and take a stand.

Universities and scientific societies do not usually do a good job of cultivating young leaders and developing the scientific enterprise's collective capacity for such leadership. This needs to change. We each found our early leadership pathways through senior colleagues who saw in us a willingness to speak up and volunteer. They mentored us. But such grooming of early-career leaders is often the exception rather than the rule.

In our roles as dean at a university and president of a large professional scientific society, we have tried to groom early-career leaders through several paths:

- Selecting junior colleagues for speaking engagements or as panel members to represent the department or university unit, so that they learn how to speak from that perspective rather than only from the point of view of their own research or self-interest.

- Populating society technical committees with $\mathrm{PhD}$ students and postdocs to give them insight into organizational practices.

- Encouraging new faculty members to serve on departmental or other committees to learn about hiring practices, merit and tenure standards.

- Presenting leadership opportunities as just that: opportunities, not unwanted service obligations. - Soliciting opinions from earlycareer scientists and encouraging them to speak up in departmental and professional society meetings.

- Including early-career scientists on society awards committees to show them what constitutes scientific excellence and how it is rewarded, and to help them to form opinions about it.

- Encouraging postdocs to participate in faculty meetings to learn how university politics work, how decisions are made and some of the constraints that limit action.

Senior faculty members are busy and often overlook the potential for junior researchers to contribute. These mindsets limit our ability to see and shape young leaders.

Leadership training can help younger colleagues to feel more confident in many roles, such as channelling the concerns of muzzled government scientists to the media; leading action groups within professional societies to take principled stands; chairing important committees and task forces that demonstrate the value of science; and articulating the value of evidence-based decisionmaking and the perils of fake news. These strengthen scientists as leaders and leaders as scientists.

Senior faculty members can mentor junior colleagues and help them to see that leadership begins in small, informal roles. As an academic community, we need to become more articulate, persuasive and influential in holding up the values of science and the leadership that this requires, in all its forms. Grooming the next generation of leaders is a crucial step towards this goal.

Toddi A. Steelman is director of the School of Environment and Sustainability at the University of Saskatchewan in Saskatoon, Canada. Jeffrey J. McDonnell is professor of hydrology and associate director of the Global Institute for Water Security at the University of Saskatchewan.

\section{PHD PROGRAMMES}

\section{Doctorate deluge}

US higher-education institutions awarded a total of 55,006 research doctoral degrees in 2015, the highest number since the US National Science Foundation launched its annual Survey of Earned Doctorates in 1957. Threequarters of those degrees were in science and engineering.

The number of recipients of science and engineering doctorates has more than doubled since 1975. And since 1995, the number of women receiving such doctorates has nearly doubled, with women earning almost half of the science and engineering PhDs awarded in 2015. The fastest-growing subfields for women were bioengineering and biomedical engineering, with an increase of more than $280 \%$ in PhDs awarded to women in those fields between 2005 and 2015.

Almost one-quarter of the science and engineering doctoral degrees awarded in 2015 were in the life sciences. Women earned slightly more than half of those.

In 2015, more $\mathrm{PhD}$ recipients of both genders reported intending to pursue postdoctoral research than were planning to pursue full-time permanent employment.

Female $\mathrm{PhD}$ recipients who had lined up postdoctoral positions reported being offered higher pay than did their male counterparts in a number of science and engineering fields, including agricultural sciences, health, physics and astronomy.

Of the doctoral recipients who were heading to non-postdoctoral positions, women were more likely to be working in academia (49\%) than in industry (26\%), whereas men's plans were more evenly split ( $42 \%$ academia, $39 \%$ industry). And more than half of men planning to seek such positions reported that research and development would be their primary activity, compared with $40 \%$ of women.

The vast majority of women who said they were heading to a non-postdoctoral position reported offers of lower salaries across all fields than did their male counterparts, with one exception: fulltime jobs in physics and astronomy were offering women a median annual salary of US $\$ 97,750$, compared with $\$ 95,000$ for men.

For both men and women, the highest-paid science and engineering fields were mathematics and computer sciences, physics and astronomy, and engineering.

The report warns that the value of a US PhD may decline as universities in other nations step up their own doctoral programmes. 